\title{
SEMANTIC EVIDENCE AGAINST THE AUTONOMY OF THE LEXICON
}

\author{
Rudolf P. Botha
}

1. This paper deals at two levels with the question of whether there is a separate component of the grammar that is specifically concerned with the structure of words. ${ }^{1}$ At a more concrete level, the paper presents semantic evidence from Afrikaans against the position that the lexicon exists as a separate word formation component. And, at a more abstract level, the paper articulates a basic condition which discussions of the question of the autonomy of the lexicon have to meet in order to be minimally coherent.

The question of the autonomy of the lexicon has recently received conflicting answers within the framework of generative morphology. Mohanan (1982:71), on the one hand, has contended that "... the principles governing the structure, meanings, as well as the phonology of words are to be distinguished from the principles governing the structure, meanings, and phonology of sentences". This contention has formed the basis for theories of word formation that provide for a lexicon or word formation component that exists as a highly structured component distinct from other parts of the grammar. Theories of Lexical Phonology and Morphology (LPM) are cases in point.

Sproat (1987:193), on the other hand, has rejected the contention of Mohanan's quoted above and, along with it, theories of the LPM type as well. He has argued that the principles of word syntax and word phonology do not differ from principles applying to other parts of the grammar. And sproat has concluded that the lexicon does not exist as a separate word formation component. In sproat's view the 
Botha, 20

lexicon, as a word formation component, can be "derived" from principles of grammar and "lexical requirements of formants". 2

Sproat has not, however, considered Mohanan's claim that the principles governing the meanings of words are to be distinguished from the principles governing the meanings of sentences. What I will do below is to show that there is a certain kind of semantic evidence that bears negatively on this claim of Mohanan's. Specifically, I will present a sample of the kind of evidence indicating that morphologically complex words formed in Afrikaans and Xhosa by means of reduplication and derivation obey the same conditions on conceptual well-formedness as do related phrases. The argument proceeds from the assumption that semantic structures are in essence conceptual structures, an assumption central to Jackendoff's (1983) theory of cognitive semantics.

2. To get to the more concrete level of the discussion: note that iteration can be expressed in Afrikaans by reduplicating a verb or by prefixing ge- or suffixing -ery to. a verb:

(1) (a) Hy skop die deur.

he kick the door

"He kicks the door."

(b) Hy skop-skop die deur.

he kick kick the door

"He kicks the door repeatedly."

(c) sy $\left\{\begin{array}{l}\text { ge }+ \text { skop } \\ \text { skop +ery }\end{array}\right\} \quad$ van die deur was irriterend.

his kicking of the door was irritating

"His repeated kicking (of) the door was irritating." 3 
Botha, 21

Not all verbs, however, can be reduplicated, prefixed with ge- or suffixed with -ery to express iteration:

(2) (a) Hy sluit die deur.

he lock the door

"He locks the door."

(b) *Hy sluit-sluit die deur.

he lock lock the door

"He locks the door repeatedly."

(c) *sy $\left\{\begin{array}{l}\text { ge }+ \text { sluit } \\ \text { sluit tery }\end{array}\right\}$ van die deur om twaalf-uur

his locking of the door at twelve o'clock

laasnag was irriterend.

last night was irritating

"His repeated locking of the door at twelve o'clock last night was irritating."

I cannot think of a principled formal explanation for the fact that whereas skop (= "kick") can be reduplicated or affixed to express iteration, sluit (= "lock") cannot. The difference in acceptability between on the one hand skop-skop (in (1)(b)), ge + skop (in (1)(c)) and skop + ery (in $(1)(c)$ ) and on the other hand sluit-sluit (in (2)(b)), ge $+\operatorname{sluit~(in~(2)(c))~}$ and sluit + ery (in (2)(c)), however, can be explained by invoking a condition of conceptual well-formedness proposed in (Botha 1988:113-115):

If an event/act has the property of "finality", it cannot occur/be performed more than once in a relatively short time-span unless a "reversing" or "resetting" event/act has intervened.

Repeated kicking (of a door) without intervening "unkicking" (of the door) is possible, hence the acceptability of (1) 
Botha, 22

(b) and (c). Repeated locking (of a door), however, is not possible without intervening unlocking (of the door), hence the unacceptability of (2)(b) and (c).

Iteration can, however, be expressed in Afrikaans by syntactic means as well: in (4)(b) by the adverb or (minimal) adverbial phrase herhaaldelik (= "repeatedly"), in (4)(c) by the noun phrase herhaalde male (= "repeated times"), and in (4) (d) by the prepositional phrase by herhaling (= "by repetition"):

(4) (a) Hy skop die deur. (= (1)(a))

(b) Hy skop die deur herhaaldelik.

he kick the door repeatedly

"He kicks the door repeatedly."

(c) Hy skop die deur herhaalde male.

he kick the door repeated times

"He kicks the door repeatedly."

(d) Hy skop die deur by herhaling.

he kick the door by repetition

"He kicks the door repeatedly."

Notice now that skop (= "kick") cannot be replaced by sluit (= "lock") in sentences (4)(b)-(d) IF these incorporate an adverbial phrase such as om twaalfuur vannag (= "at twelve o'clock tonight") as is clear from the unacceptability of $(5)(b)-(d)$ :

(5) (a) Hy sluit die deur. (= (2)(a))

(b) *Hy sal die deur herhaaldelik om twalfuur he will the door repeatedly at twelve o'clock vannag sluit.

tonight lock

"He will lock the door repeatedly at twelve 
Botha, 23

(c) *Hy sal die deur herhaalde male om twaalfuur he will the door repeated times at twelve $0^{\prime} \mathrm{clock}$ vannag sluit. tonight lock

"He will lock the door repeatedly at twelve o'clock tonight."

(d) *Hy sal die deur by herhaling om twaalfuur he will the door by repetition at tvelve o'clock vannag sluit. tonight lock

"He will lock the door repeatedly at twelve o'clock tonight."

But the difference in acceptability between the (4) and corresponding (5) sentences can be explained with reference to the condition (3) of conceptual well-formedness. Sentences (4) (b)-(d) obey condition (3): the act of kicking lacks the property of finality mentioned in the condition and can be repeated in a relatively short time-span, without the intervention of a reversing act. Sentences (5)(b)-(d), by contrast, violate condition (3), hence their unacceptability.

This, of course, is to say that a condition of conceptual well-formedness proposed for morphologically complex words applies to the meaning of sentences/phrases too. To put it another way: what appear to be (semantic) restrictions on the productivity of morphological processes of reduplication and affixation can be "derived" from conditions of conceptual wellformedness that apply to the meaning of both words and sentences. But, in terms of Mohanan's position, this should not be the case if the lexicon were independent of the syntax. This independence can be bought at the cost of duplicating condition (3) --- or a functionally equivalent device --- in the grammar, thereby creating a redundancy and missing a generalization. This, obviously, is too high a price to pay for upholding the autonomy of the lexicon, especially if it is kept in mind that there are a consicierable number of conditions of 
Returning to the Afrikaans data, as far as their "conceptual" properties are concerned, skop and sluit are in no way unique or exceptional. Both are typical representatives of categories of verbs that can be given an independent characterization. Thus, it is observed in (Botha 1988:114) that sluit represents the category of verbs that denote what vendler (1967:103) has called "achievements": events or acts that occur in a single moment of time and that cannot be extended in time or be repeated in a relatively short time-span. other typical verbs of achievement are arriveer (= "arrive"), bereik ( = "reach"), vergeet (= "forget"), and onthou (= "recall"). Like sluit, these verbs cannot be used in morphological and syntactic forms such as those of (2) and (5) to express iterativity. skop, by contrast, is a typical representative of the category of "non-achievement" verbs, a category whose other members can be used in morphological and syntactic forms such as those in (1) and (4) above.

3. The condition (3) on conceptual well-formedness is by no means the only one that applies to the meaning of both morphologically complex words ard sentences in Afrikaans. There are various others, one of which is a condition on the expression of serial ordering. The idea that certain things or events are serially ordered can be expressed by reduplicating a noun, by suffixing-gewys(e) (= "-wise") to the noun or by using the noun in a vir (= "for") or na ( = "after") phrase:

(6) (a) Hy krap in laag van die verf af. he scrape a layer of the paint off "He scrapes a layer of the paint off."

(b) Hy krap die verf laag - laag af. he scrape the paint layer layer of $f$ "He scrapes the paint off in one layer after another." 
(c) Hy krap: die verf laags + gewys(e) af. he scrape the paint layer wise off "He scrapes the paint off in one layer after another."

(d) Hy krap die verf laag vir laag af. he scrape the paint layer for layer off "He scrapes the paint off in one layer after another."

(e) Hy krap die verf laag na laag af. he scrape the paint layer after layer of "He scrapes the paint off in one layer after another."

Not all nouns, however, can be reduplicated or suffixed with -gewys(e), or used in a vir or na phrase to express serial ordering. This observation may be illustrated with reference to the noun blaas (= "blister"):

(7) (a) Hy krap in blaas in die verf af. he scrape a blister in the paint off "He scrapes a blister in the paint off."

(b) *Hy krap die verf blaas - blaas af. he scrape the paint blister blister off "He scrapes the paint off in one blister after another."

(c) *Hy krap die verf blaas + gewys(e) af. he scrape the paint blister wise off "He scrapes the paint off in one blister after another."

(d) *Hy krap die verf blaas vir blaas af. he scrape the paint blister for blister off "He scrapes the paint off in one blister after another." 


(e) *Hy krap die verf blaas na blaas af.
he scrape the paint blister after blister off
"He scrapes the paint off in one blister after
another."

Whereas laag (= "layer") can be reduplicated (in (6)(b)) and suffixed with-gewys(e) (in (6)(c)) to express serial ordering, blaas (= "blister") (in (7)(b) and (c)) cannot. Likewise, whereas laag can be used in a vir phrase (in (6)(d)) and a na phrase (in (6)(e)) to express serial ordering, blaas (in (7) (d) and (e)) cannot.

I have been unable to find a formal explanation for this difference in behaviour between laag and blaas. But it can be explained by invoking the following condition of conceptual well-formedness:

If a thing can be conceptualized as being made up of certain parts, it is conceivable that someone/something can affect the thing by doing something to the parts one after another. 4

Conceptually, the sentences $(6)(b)-(e)$ do not violate this constraint: a coat of paint can be thought of as made up of various layers to which something may be done one after another. A coat of paint, however, is not normally thought of as made up of blisters. But this is presupposed in the meaning of the sentences (7) (b)-(e), hence their bizarreness.

Notice that condition (8) applies to the meaning of both morphologically complex words and phrases or sentences. One would not have expected this to be the case, given Mohanan's view that the lexicon is wholly independent of the syntax. 
4. There is evidence that such conditions of conceptual well-formedness as (3) and (8) are not language-specific. For example, in Xhosa and South Sotho the expression of iterativity appears to be subject to condition (3) as well. 5 This point may be illustrated with reference to the following Xhosa expressions:

(9)

(a) ucango. (cf. (1)(a))
$u$-khab-a ucango
AGR-kick-Pres door
"He kicks the door."

(b) Ukhaba - khaba ucango. (cf. (1)(b))

u - khab-a - khab-a ucango

AGR-kick-Pres-kick-Pres door

"He kicks the door repeatedly."
(c) Ukukhabana nocango kwakhe
uku -khab-an -a na -ucango kwa-khe
Infin-kick-Rec-Pres with-door Gen-he

bekucaphukisa. (cf. (1)(c))

beku-caphukisa

AGR (Past)-irritate

"His repeated kicking of the door was irritating."

(10)
(a) Utshixa
ucango.
(cf. ( 2$)(a))$
u - tshix-a
ucango
AGR-lock-Pres door
"He locks the door."
(b) *utshixa - tshixa ucango. (cf. (2) (b))


Botha, 28

(c)

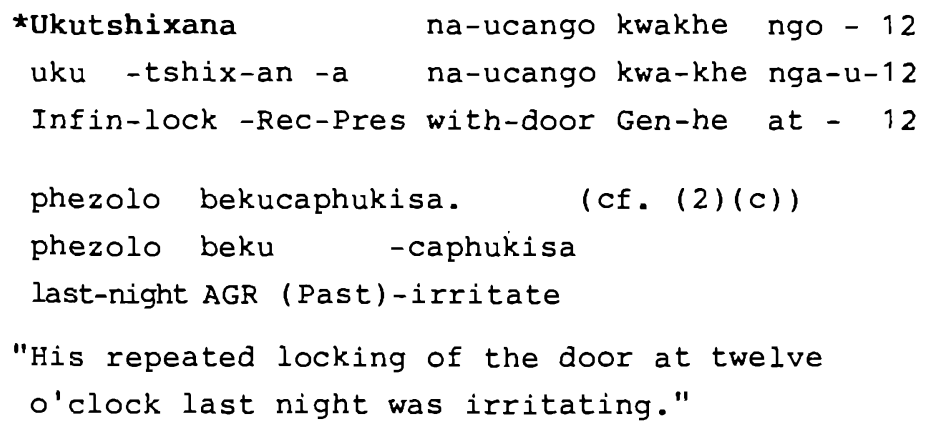

(11) (a) Ukhaba ucango. (cf. (4)(a))

(b) Ukhaba ucango futhi/gho. (cf. (4)(b))

$u$-khab-a ucango futhi/gho

AGR-kick-Pres door repeatedly

"He kicks the door repeatedly."

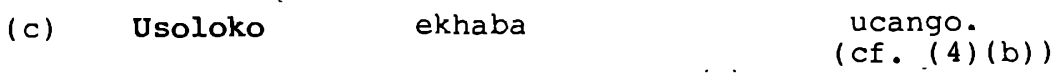

u -soloko e - -khab-a ucango

AGR-repeatedly AGR (Partic)-kick-Pres door

"He kicks the door repeatedly."

(12) (a) Utshixa ucango. $(=(10)(a))($ cf. $(5)(a))$

(b) *utshixa ucango futhi/qho. (cf. (5)(b))

u -tshixa ucango futhi/gho

AGR-lock door repeatedly

"He locks the door repeatedly."

(c) *Usoloko etshixa ucango:

(cf. (5) (b))
u - soloko
e - - tshix a
ucango
AGR-repeatedly AGR (Partic)-lock-Pres door
"He locks the door repeatedly." 


(d) *Ukusoloko $\begin{array}{llll}\text { etshixa } & \text { ucango } \\ \text { Uku -soloko } & \text { e }- & \text { tshix-a ucango } \\ \text { Infin-repeatedly AGR (Partic)-lock-Pres door }\end{array}$
kwakhe ngo -12 phezolo beku
kwa-khe nga-u-12 phezolo beku
Gen-he at - 12 last night AGR (Partic)-
caphukisa.
caphukisa
irritate
"His repeated locking of the door at twelve
o'clock last night was irritating."

These Xhosa expressions are in three respects interesting within the framework of the present discussion. First, like Afrikaans, Xhosa uses reduplication (cf. (9)(b)), affixation (cf. the an- Suffixation in (9)(c)), and syntactic means (cf. (11)(b) and (c)) to express iterativity. Second, as is clear from the starred expressions (cf. (10)(b) and (c), (12)(b), (c) and (d)), the expression of iterativity in xhosa is subject to the condition (3) of conceptual well-formedness as well. This condition, clearly, is not specific to Afrikaans. Third, Xhosa provides independent semantic evidence indicating that the lexicon does not exist as separate word formation component in Mohanan's sense. The meaning of the Xhosa words and phrases considered above obey one and the same condition of conceptual well-formedness.

5. Moving on to the more general level, let us note that, for a discussion of the question of the autonomy of the lexicon to be minimally coherent, general assumptions such as the following have to be made: 
(13) (a) If the structures or representations generated/defined by a putative component are governed by principles that apply elsewhere in the grammar as well, this component cannot be claimed to be autonomous.

(b) The autonomy of a component of grammar cannot be bought either at the cost of conceptual redundancy or by the sacrifice of generalization.

(c) A grammar has to account not only for syntactic and phonological well-formedness, but for conceptual well-formedness as well.

Assumptions such as (13)(a)-(c) represent defining principles of general-linguistic theories or paradigms.' This means that to be minimally coherent, discussions of the autonomy of the lexicon --- or, for that matter, of any other component of the grammar -- are necessarily "theory-bound" or "paradigm-internal". Linguists who work within the framework of theories or paradigms that do not share fundamental assumptions such as (13)(a)-(c) cannot argue in a coherent manner about the "autonomy of the lexicon". Instead, these linguists should be arguing about the relative merits of theory or paradigm defining assumptions such as (13)(a)-(c). 
Botha, 31

\section{NOTES}

1. A first version of this paper was presented at The Third International Morphology Meeting (3-7 July 1988, Krems, Austria).

2. Lieber (to appear:3), too, has recently argued for the position that "The lexicon itself does not contain any rules or principles which put together derived, inflected or compounded words. Rather, these are generated using solely the principles made available by the syntax".

3. Complex forms such as ge + skop + ery incorporating both the prefix ge- and the suffix -ery can be freely formed in Afrikaans. Neither the internal bracketing nor the semantic interpretation of such forms is relevant to the basic point at issue in this paper. For some discussion of such complex forms $c f$. Kempen 1969:468ff.

4. Within the context of this condition, a thing can be a set and parts can be the members of such a set.

5. I would like to sincerely thank Marianna Visser for the Xhosa data. I am also much indebted to Justus Roux for sotho data that have the same basic import. 


\section{REFERENCES}

Botha, R.P. 1988. Form and meaning in word formation. A study of Afrikaans reduplication. Cambridge, etc.: C.U.P.

Jackendoff, R. 1983. Semantics and cognition. Cambridge, Mass.: MIT Press.

Kempen, W. 1969. Samestelling, afleiding, en woordsoortelike meerfunksionaliteit in Afrikaans. Kaapstad, ens.: Nasou Beperk.

Lieber, R. to appear. Phrasal compounds in English and the morphology-syntax interface. CIS 24-II.

Mohanan, K.P. 1982. Lexical phonology. Doctoral dissertation. IULC.

sproat, R. 1987. On deriving the lexicon. The Linguistic Review 5:185-196.

Vendler, Z. 1967. Linguistics and philosophy. Ithaca, New York: Cornell University Press. 